\title{
Selective reaching: distracter effects on movement kinematics as a function of target-distracter separation
}

Citation for published version (APA):

Keulen, R. F., Adam, J. J. M. E., Fischer, M. H., Kuipers, H., \& Jolles, J. (2004). Selective reaching: distracter effects on movement kinematics as a function of target-distracter separation. Journal of General Psychology, 131(4), 345-363. https://doi.org/10.3200/GENP.131.4.345-364

Document status and date:

Published: 01/01/2004

DOI:

10.3200/GENP.131.4.345-364

Document Version:

Publisher's PDF, also known as Version of record

Please check the document version of this publication:

- A submitted manuscript is the version of the article upon submission and before peer-review. There can be important differences between the submitted version and the official published version of record.

People interested in the research are advised to contact the author for the final version of the publication, or visit the DOI to the publisher's website.

- The final author version and the galley proof are versions of the publication after peer review.

- The final published version features the final layout of the paper including the volume, issue and page numbers.

Link to publication

\footnotetext{
General rights rights.

- You may freely distribute the URL identifying the publication in the public portal. please follow below link for the End User Agreement:

www.umlib.nl/taverne-license

Take down policy

If you believe that this document breaches copyright please contact us at:

repository@maastrichtuniversity.nl

providing details and we will investigate your claim.
}

Copyright and moral rights for the publications made accessible in the public portal are retained by the authors and/or other copyright owners and it is a condition of accessing publications that users recognise and abide by the legal requirements associated with these

- Users may download and print one copy of any publication from the public portal for the purpose of private study or research.

- You may not further distribute the material or use it for any profit-making activity or commercial gain

If the publication is distributed under the terms of Article $25 \mathrm{fa}$ of the Dutch Copyright Act, indicated by the "Taverne" license above, 


\title{
Selective Reaching: Distracter Effects on Movement Kinematics as a Function of Target-Distracter Separation
}

\author{
RON F. KEULEN \\ Department of Psychiatry and Neuropsychology \\ Maastricht University, The Netherlands \\ JOS J. ADAM \\ Department of Movement Sciences \\ Maastricht University, The Netherlands \\ MARTIN H. FISCHER \\ Department of Psychology \\ University of Dundee, Scotland \\ HARM KUIPERS \\ Department of Movement Sciences \\ Maastricht University, The Netherlands \\ JELLE JOLLES \\ Department of Psychiatry and Neuropsychology \\ Maastricht University, The Netherlands
}

\begin{abstract}
The authors investigated distracter effects on the kinematics of reaching movements to determine when during reaching responses (reaction time, time to peak velocity, time after peak velocity, or peak velocity) distracter interference occurred and how target-distracter separation affected the locus of interference. Participants moved a pen on a digitizing tablet toward a target appearing with or without a distracter. With a small target-distracter separation, distracter interference occurred during time after peak velocity (similar amounts of interference from near and far distracters). With a large target-distracter separation, distracter interference occurred during time to peak velocity (more interference from near compared to far distracters). The results demonstrated that target-distracter separation is an important determinant of the locus of distracter interference.
\end{abstract}

Key words: distracter interference, kinematics, reference frames, selective reaching 
HUMAN BEHAVIOR IS CHARACTERIZED by a high degree of selectivity. Imagine a person reaching for a specific glass of beer from a table on which there are many other glasses. All glasses evoke a similar action (i.e., reaching for it), but one does not end up reaching for all of the glasses. How is that accomplished? The problem can be solved by means of selectivity; one's mind selects a glass from the multitude of perceptual inputs, and one acts on the basis of the perceptual input and picks up that specific glass (Tipper, Howard, \& Houghton, 1998; Tipper, Lortie, \& Baylis, 1992).

Although selectivity enables us to deal properly with the enormous amounts of perceptual inputs, it does not follow that our actions are unaffected by the mere presence of irrelevant inputs. Researchers have studied extensively the concept of selectivity, as illustrated by the aforementioned real-life example, in various experimental set-ups, and they have shown that the presence of a distracting (i.e., irrelevant) stimulus can affect the response to the desired target (i.e., relevant) stimulus.

Tipper et al. (1992) studied the concept of selectivity in a selective reaching task. Selective reaching requires reaching directly toward an object while ignoring other objects in the visual scene. In Tipper et al.'s selective reaching task, a board containing a set of buttons was placed on a table in front of the participant. The participants had to depress the button with the red light adjacent to it and to ignore a yellow light that was presented simultaneously near another button. Tipper et al. found that response times (RTs) were lengthened by the presence of a distracter (yellow) light, and that was called distracter interference. Moreover, near distracters (i.e., distracters located between the starting position of the hand and the target) seemed to cause more interference than did far distracters (i.e., distracters located behind the target). That asymmetric pattern of interference is called the proximity-to-hand effect. The finding of the link between interference and the starting position of the responding hand was replicated when the stimulus board was turned around so that the start button was at the top of the board. Tipper et al. interpreted their findings as evidence for an action-centered account of selective attention. That is, attention gains access to an action-centered frame of reference when actions are aimed directly at objects whose position is defined relative to the responding effector. Within an action-centered frame of reference, objects in the environment are coded relative to the starting position of the effector, because the primary task is to move the effector toward the target.

Meegan and Tipper (1999) postulated the Visuomotor Processing Hypothesis to explain the proximity-to-hand effect. According to the hypothesis, one assumes that interference is a result of visuomotor competition from distracters. The faster a movement can be made to a location, the greater the interference caused by a distracter at that location. That is because the efficiency of visuomotor processing

Address correspondence to Ron F. Keulen, Department of Psychiatry and Neuropsychology, Maastricht University, P.O. Box 616, 6200 MD, Maastricht, The Netherlands; r.keulen@np.unimaas.nl (e-mail). 
(i.e., response planning and execution) depends on the location of the stimulus. More specifically, near locations seem to have a visuomotor processing advantage relative to far distracters. As a result, the advancement of the visuomotor representation of the distracter is greater for near distracters compared with far distracters, which results in more competition (which means more interference).

Keulen, Adam, Fischer, Kuipers, and Jolles (2002) replicated the method of Tipper et al. (1992), and they also found a proximity-to-hand effect, but only with large (i.e., 20-mm) target-distracter separations. With small (i.e., 5-mm) separations, near and far distracters caused similar amounts of interference. Keulen et al. interpreted those findings as evidence for the involvement of multiple frames of reference in selective reaching. With large target-distracter separations, an action-centered frame of reference dominates performance, whereas with small separations, an environment-centered frame of reference dominates. In an environment-centered frame of reference, locations of objects are coded relative to other objects in the environment.

Keulen et al. (2002) argued that the selection problem that has to be solved when reaching for a target that is accompanied by a distracter depends on the spatial relationship between target and distracter. On the one hand, when the target and distracter are close to each other, there might be two selection problems to solve. One is to determine the general location of the target-distracter area. That problem arises relatively early (i.e., during response planning) and may benefit from an action-centered frame of reference, because the critical task is to move the hand to the vicinity of the target. The second selection problem is to distinguish the exact location of the target relative to the distracter. That particular problem arises later (i.e., during response execution), when the hand approaches the target-distracter area. An environment-centered frame of reference would likely help with solving the second problem because the critical task would then be to terminate the movement at the target, rather than at the distracter.

On the other hand, when there is a relatively large separation between the target and the distracter, the selection problem concerns determining the spatial location of the target. That problem has to be solved in an early (i.e., planning) stage to prevent programming an incorrect response (i.e., a movement to the distracter instead of to the target). Hence, the temporal locus of distracter interference may critically depend on target-distracter separation, and thus occur both early and late (in the case of small target-distracter separations) or only early (in case of large target-distracter separations).

The aim of the present study was to test the hypothesis that target-distracter separation in a selective reaching task could determine the temporal locus of distracter interference. In Experiment 1, we used a small (i.e., 5-mm) target-distracter separation. The hypothesis we sought to test predicted both early (i.e., action-centered) and late (i.e., environment-centered) interference, because of the two selection problems to be solved in close temporal proximity. Early interference may affect the preplanned portion of the response (i.e., 
time to peak velocity and/or peak velocity), whereas late interference may affect the feedback-controlled portion of the response (i.e., time after peak velocity). In Experiment 2, we used a large (i.e., 20-mm) distance between target and distracter. In that case, only early (i.e., action-centered) interference was expected, which affected time to peak velocity and/or peak velocity. We expected that the later part of the response would be free of interference effects because they had been resolved during the early part of the response.

Although the aim was to investigate how distracters might affect movement kinematics, we expected that response preparation might also be influenced by a distracting stimulus. Several researchers (e.g., Meegan \& Tipper, 1998; Pratt \& Abrams, 1994) have found that distracter interference and, more specifically, the proximity-to-hand effect occurred in both reaction time and movement time. In the present experimental set-up (for Experiments 1 and 2) the initial movement direction was constant (i.e., all movements were left-to-right movements), which allowed for target selection to occur after movement initiation (see also Keulen et al., 2002). Interference was therefore likely to accrue during response execution, which explains our special interest in the kinematics of the aiming response. Nonetheless, for the sake of completeness, we also assessed distracter effects in reaction time.

Before we describe the experiments in our study, we would like to address a methodological point. Participants can adopt different control modes to minimize total movement times when they reach for a target (Meyer, Abrams, Kornblum, Wright, \& Smith, 1988). One option is to produce a high-velocity initial impulse. Such an initial impulse will be short in duration, but often will result in the participant missing the target region. As a result, total movement time will increase because of the need for error correction. Another option is to generate initial impulses with low velocities so that they are more accurate. However, that also results in long total movement times. Thus, optimizing performance requires an ideal compromise between initial impulse duration and error correction duration (Khan, Franks, \& Goodman, 1998; Meyer et al.). To prevent the results from being a joint function of various control modes, we decided to differentiate between trials with and without discrete movement modifications. Our preliminary data analyses indicated that discrete movement modifications occurred only on a relatively small percentage of all trials (i.e., $18.2 \%$ and $14.3 \%$, in Experiments 1 and 2, respectively), so we chose to focus on trials that did not have discrete modifications.

\section{EXPERIMENT 1: Small Target-Distracter Separation}

In Experiment 1, we examined the effect of a distracter on the kinematics of target-directed reaching movements when there was a small (i.e., 5-mm) target-distracter separation. The goal was to determine how key kinematic variables such as time to peak velocity, peak velocity, and time after peak velocity were 
influenced by the presence of (near and far) distracters. If, as outlined heretofore, the use of small target-distracter separations poses two selection problems (one early and one late), then one would expect interference to occur in time to peak velocity and/or peak velocity (i.e., early) and in time after peak velocity (i.e., late). In addition, we inspected the RTs for interference effects to replicate the findings of Tipper et al. (1992).

\section{Method}

\section{Participants}

Sixteen students from Maastricht University, 9 women and 7 men, with a mean age of 21.1 years (range: 18-24), participated in Experiment 1 . In this experiment and in Experiment 2, the participants were paid the equivalent of about $\$ 4$, were right-handed, had normal or corrected-to-normal visual acuity, and were naive as to the purposes of the experiment.

\section{Apparatus and Stimuli}

The participants were tested individually in a quiet, dimly lit room. They sat on a height-adjustable chair in front of a PL-400 V1.3-4 digitizing tablet (Wacom) that was equipped with an embedded LCD-screen (screen diagonal = $14 \mathrm{in.}$.). The far end of the tablet was raised to an angle of $20^{\circ}$, and the participants recorded their responses with a handheld PL-400 pen (Wacom) directly onto the screen. The participants were positioned so that the body midline was in line with the start box on the left side of the tablet. The stimulus display that was used in the experiment is schematically depicted in Figure 1. The start box and the stimulus boxes were presented as squares in black outline on a white
A. $\quad$ Start box

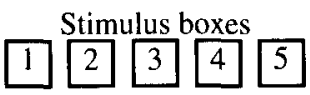
B. Start box
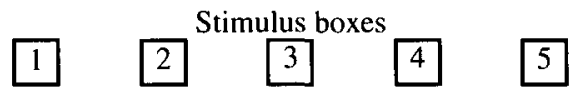
FIGURE 1. Schematic overview of the stimulus displays used in the present study. The square with the circle inside denotes the start position of the pen. The num- bers 1 to 5 indicate the potential stimulus locations. Drawn to scale. The num- bers were not actually present. $A$ and $B$ indicate the small-separation (Experi- ment 1) and the large-separation (Experiment 2) conditions, respectively. 
background. A circle (diameter $=1.5 \mathrm{~mm}$ ) was located at the center of the start box. The target stimulus was presented as a solid green square that filled one of the stimulus boxes. The distracter stimulus was presented as a solid red square that completely filled one of the boxes directly adjacent to the target box. From the participant's perspective, the distracter stimulus could appear either to the left or to the right of the target stimulus. However, we will use the terms near distracter and far distracter to refer to distracters that appear to the left and to the right of the target, respectively, to describe where the distracter was in relation to the starting position of the hand. All boxes were $10 \mathrm{~mm}$ wide and high. One should note, however, that for defining an aiming error, the effective target width was set at $12 \mathrm{~mm}$. That was done to limit the number of errors (i.e., target misses). The five stimulus boxes were arranged in a horizontal array spanning $7 \mathrm{~cm}$, with a distance of $5 \mathrm{~mm}$ between the individual stimulus boxes (sideto-side). The starting box was located $14 \mathrm{~cm}$ to the left of this array (side-to-side).

The digitizing tablet was interfaced with an MS-DOS Pentium II computer equipped with a Matrox Millennium G400 DualHead Max graphical card. The OASIS 833 software package (KIKO Software, 1999) controlled stimulus presentation and recorded the spatial, temporal, and kinematic data. The temporal resolution was $5 \mathrm{~ms}$, and the spatial resolution was $0.5 \mathrm{~mm}$.

\section{Design}

The participants performed in a single session that lasted about $20 \mathrm{~min}$. There were 195 test trials, which were preceded by 25 practice trials. Within a block of 195 test trials, there were 75 trials without a distracter (i.e., 15 for each target) and 120 trials with a distracter. For the distracter trials, Targets 2, 3, and 4 (as labelled in Figure 1) each had 15 trials with a near distracter and 15 trials with a far distracter, whereas Target 1 had only 15 trials with a far distracter, and Target 5 had only 15 trials with a near distracter. The order of distracter and no-distracter trials within a block of 195 test trials was random.

\section{Procedure}

The participants were informed that on each trial, a green light would appear in one of the five stimulus boxes and that on some trials, a red light would appear in a different box. At the beginning of each trial, the participant had to place the pen tip in the start box circle and keep it there until the target stimulus appeared. After $5 \mathrm{~ms}$ of keeping the pen tip stationary at the starting position, the target stimulus (with or without distracter) appeared and remained on until the response was completed. The participants were instructed to move the pen as quickly and as accurately as possible toward the green target box and to stop there, while ignoring the red distracter box. Five-hundred $\mathrm{ms}$ after the completion of the response, 
the stimulus boxes were cleared, signaling the start of the next trial, which the participants could initiate at will. To ensure that the participants placed the pen in the start box circle, they were instructed to visually fixate on the starting position until stimulus presentation took place. The pen had to be kept on the tablet while it was being moved. If the participants missed the target, they were encouraged to try to do better in subsequent trials. The computer presented a visual feedback signal if the participant failed to hit the stimulus box ("You missed the target!") or if the pen was released from the tablet before completion of the response ("Keep the pen on the tablet!"). These erroneous trials were not repeated.

\section{Movement Analysis}

To differentiate between trials with and without discrete error corrections, we used a method that was based on the movement-parsing algorithm developed by Meyer et al. (1988). We were particularly interested in error corrections that were characterized by a speeding up after a slowing down because typically, that type of correction reflects a discrete secondary movement. ${ }^{1}$ Trials in which such a correction was identified were removed from further analyses. This resulted in the removal of $18.2 \%$ of all trials.

We calculated three temporal measures: (a) reaction time (RT), measured from the time that the target stimulus appeared to the time that the movement was initiated; (b) time to peak velocity (TTPV), measured from the time that the movement was initiated to peak velocity; and (c) time after peak velocity (TAPV), measured from peak velocity to the time that the movement was terminated. Furthermore, we calculated peak velocity (PV) and percentage errors (PE). Percentage errors referred to the percentage of trials in which the target was missed.

\section{Statistical Analysis}

RTs below $150 \mathrm{~ms}$ were considered anticipations and were excluded from data analyses. Furthermore, RTs and movement times (MTs) over 1,000 ms and MTs below $150 \mathrm{~ms}$ were considered outliers and were also excluded from further analysis. Three percent of the trials were removed using those criteria $(3.3 \%$ in the no-distracter condition, $2.8 \%$ in the distracter condition).

For each of the variables listed in the section on Movement Analysis, we calculated the means for each participant as a function of distracter presence and target location. We performed two different kinds of analyses of variance (ANOVAs). The first analysis, called the analysis of distracter presence, included all data and was performed on the means of all the variables listed heretofore with distracter presence (with vs. without distracter) and target location $(1,2,3,4$, or $5)$ as within-subject variables.

In the second analysis, called the analysis of distracter location, we compared trials with near and far distracters. Following the analyses by Meegan and Tipper 
(1998), we calculated interference scores for each participant in each of the distracter conditions (i.e., near and far) in the following manner. We calculated the mean RTs, TTPVs, TAPVs, PVs, and PEs for all distracter and target-only conditions. Then we calculated the differences between the mean RT, TTPV, TAPV, PV, and PE for each target-distracter combination and its respective control (i.e., RT, TTPV, TAPV, PV, and PE for the same target without a distracter). We calculated interference scores for each participant in each distracter condition (i.e., near and far) by taking a mean of all difference scores in a particular distracter condition.

We used the Huynh-Feldt corrected significance values to adjust the tests for heterogeneity of variance and covariance whenever needed. Post hoc analyses were carried out using Tukey's honestly significant procedure; an alpha level of .05 was used to determine statistical significance.

\section{Results}

\section{Analysis of Distracter Presence}

Reaction time. The distracter presence main effect was near significant, $F(1,15)=$ $4.26, p=.057$, indicating a tendency for longer RTs in the no-distracter condition than in the distracter condition ( 321 vs. $313 \mathrm{~ms}$, respectively). All $F$ values involving the factor target location were nonsignificant (all $p s>.2$ ).

Time to peak velocity. There was a significant main effect of target location, $F(4$, $60)=14.79, p<.001$, indicating longer TTPVs for targets located further away ( $M \mathrm{~s}=213,224,228,232$, and $244 \mathrm{~ms}$ for Targets 1, 2, 3, 4, and 5, respectively). One should note that TTPV did not differ significantly between Targets 2 and 3 $(p>.3)$ and Targets 3 and $4(p>.2)$. Neither the distracter presence main effect nor the Target Location $\times$ Distracter Presence interaction were significant (all $p \mathrm{~s}>$ .4 ), indicating that distracter presence had no effect on the time to peak velocity. Mean time to peak velocity was $228 \mathrm{~ms}$ (see also Figure 2).

Time after peak velocity. The significant target-location main effect, $F(4,60)=$ $9.05, p<.001$, indicated longer TAPVs for targets located further away $(M \mathrm{~s}=$ $235,246,251,262$, and $261 \mathrm{~ms}$ for targets $1,2,3,4$, and 5, respectively). The distracter presence main effect was also significant, $F(1,15)=7.53, p<.05$, indicating a 9-ms interference effect $(M \mathrm{~s}=256$ and $247 \mathrm{~ms}$, respectively, for trials with and without distracter; see also Figure 2 ). The Target Location $\times$ Distracter Presence interaction was nonsignificant, $F(4,60)=1.94, p>.1$.

Peak velocity. Target location significantly affected the maximum movement velocity attained during the response, $F(4,60)=108.75, p<.001$. Targets located further away were associated with higher PVs $(M s=66.9,71.7,76.2,80.0$, and 83.8 


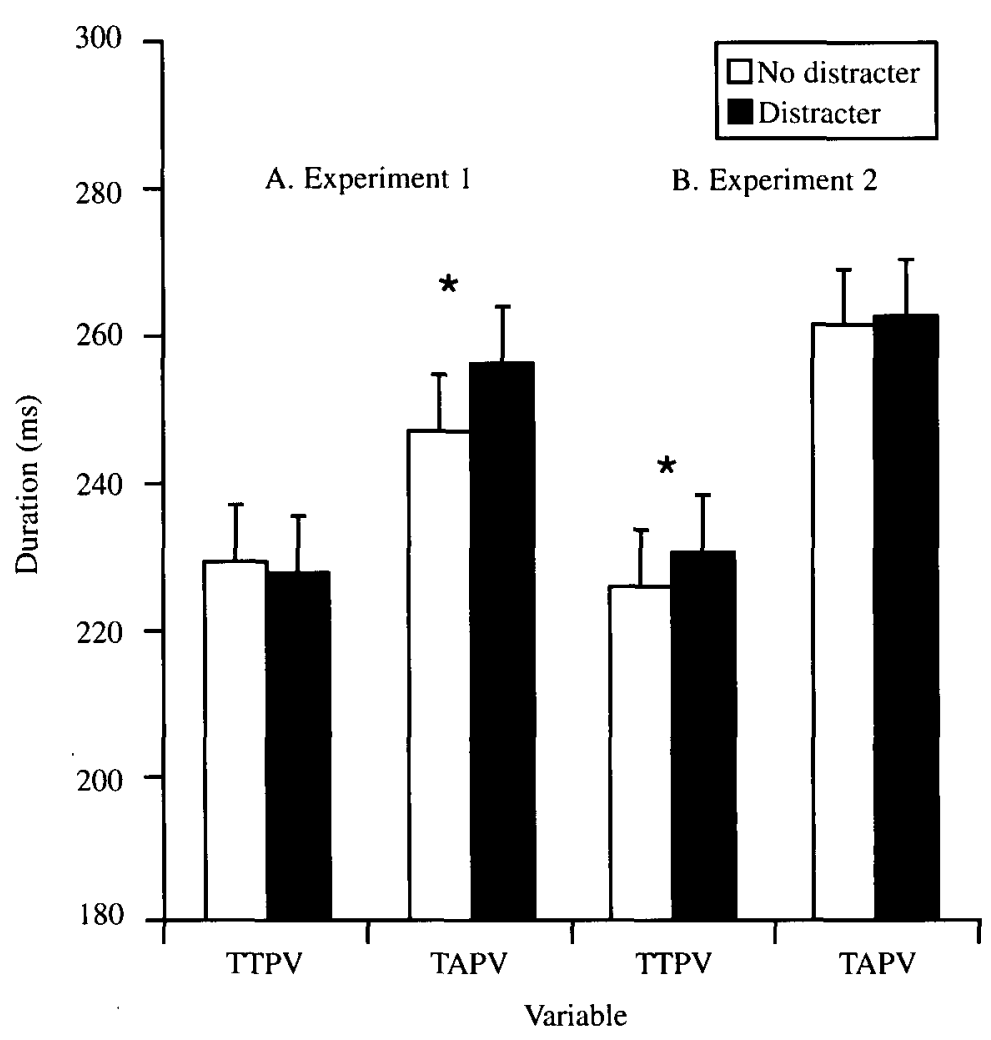

FIGURE 2. Mean time to peak velocity (TTPV) and time after peak velocity (TAPV), averaged across all target positions, as a function of Distracter Presence. The asterisks indicate significance at the .05 level. The error bars indicate the standard errors. $A$ and $B$ depict the results for the small-separation (Experiment 1) and the large-separation (Experiment 2) conditions, respectively.

$\mathrm{cm} / \mathrm{s}$ for Targets $1,2,3,4$, and 5 , respectively). The distracter presence main effect and the Distracter Presence $\times$ Target Location interaction were nonsignificant (all $p s>.4)$.

Percentage error. All $F$ values pertaining to target location and distracter presence were nonsignificant (all $p \mathrm{~s}>.2$ ). The overall error rate was $4.4 \%$.

\section{Analysis of Distracter Location}

Reaction time, time to peak velocity, time after peak velocity, and percentage errors. All $F$ values regarding distracter location were nonsignificant (all $p s>.4$ ), 
indicating that near and far distracters did not differentially interfere with those dependent measures.

Peak velocity. Near and far distracters differentially affected the maximum movement velocity attained during the response, $F(1,15)=6.37, p<.05$. That is, whereas near distracters significantly decreased peak velocity, $t(15)=-1.922, p<$ $.05, M=-0.9 \mathrm{~cm} / \mathrm{s}$, far distracters did not significantly affect peak velocity, $t(15)=$ $.926, p>.3$.

\section{Discussion}

Keulen et al. (2002) found that with small (i.e., 5-mm) target-distracter separations, distracter interference occurred in movement time and, moreover, that the amount of interference was similar for near and far distracters. We replicated these findings in Experiment 1 and showed that the interference effect was located in the time after peak velocity. These outcomes are consistent with the hypothesis that with small target-distracter separations, homing in on the target is coordinated within an environment-centered frame of reference.

In addition, the results showed that near and far distracters differentially affected peak velocity. That is, near distracters decreased peak velocity, whereas far distracters had no effect on peak velocity. These findings are consistent with the idea that initially a response will be prepared heading for the stimulus that is closest to the starting position of the responding effector (Keulen, Adam, Fischer, Kuipers, \& Jolles, 2003). In the case of a near distracter, the nearest stimulus is the distracter (which is closer to the starting position of the hand than to the target). Smaller movement amplitudes are associated with lower peak velocities (for similar findings see Jeannerod \& Prablanc, 1983; Kudoh, Hattori, Numata, \& Maruyama, 1997), which explains why near distracters lower peak velocity (relative to the target-only situation). However, in the case of a far distracter, the nearest stimulus is, in fact, the target. As a result, peak velocity in the far distracter situation will not differ or differ minimally from the target-only situation. The observation that near and far distracters differentially affected peak velocity was consistent with the hypothesis that with small target-distracter separations, distracter interference may also occur in the preplanned portion of the reaching response (i.e., early), and that that early interference is action centered in nature. In sum, the results of Experiment 1 corroborate the idea that small target -distracter separations may evoke two selection problems, one early and one late.

The results also showed that the simultaneous presentation of target and distracter tended to shorten reaction times. This finding has been reported before (Fischer \& Adam, 2001) and may be related to the fact that large stimulus ensembles (i.e., target plus distracter) contain more (stimulus) energy and therefore facilitate reaction times (Nickerson, 1973). The basic idea is that stimulus energies combine in some way so that the presentation of an accessory stimulus along 
with the primary stimulus is effectively equivalent to increasing the intensity of the latter.

\section{EXPERIMENT 2: Large Target-Distracter Separation}

In Experiment 2, we again examined the effect of a distracter on movement kinematics. This time, we used a large (i.e., 20-mm) target-distracter separation. We hypothesized that if the use of large target-distracter separations posed a single (early) selection problem, then interference would occur only in time to peak velocity and/or peak velocity.

\section{Method}

\section{Participants}

Twenty-two students from Maastricht University, 13 women and 9 men, with a mean age of 21.8 years (range: $18-28$ ), participated. None had participated in Experiment 1.

\section{Apparatus and Stimuli}

The apparatus and stimuli were identical to those used in Experiment 1, except for the spatial relationship between the start box and the stimulus boxes. In Experiment 2, the five stimulus boxes were arranged in a horizontal array spanning $13 \mathrm{~cm}$, with a distance of $20 \mathrm{~mm}$ between the individual stimulus boxes (side-to-side). The starting box was located $8 \mathrm{~cm}$ to the left of this array (side-toside; see Figure 1).

\section{Design and Procedure}

The design and procedure were the same as they were in Experiment 1.

\section{Movement Analysis}

We used the movement-parsing algorithm that was introduced in Experiment 1. On average, $14.3 \%$ of all trials contained a discrete movement modification, and those trials were removed from further data analyses.

\section{Statistical Analysis}

By using the Experiment 1 criteria for exclusion of trials, we removed $2.8 \%$ of the trials $(2.2 \%$ in the no-distracter condition, $3.3 \%$ in the distracter condition). 


\section{Results}

Analysis of Distracter Presence

Reaction time. There was a main effect of distracter presence, $F(1,21)=74.16$, $p<.001$, indicating reliably longer RTs in the no-distracter condition than in the distracter condition ( 309 vs. $291 \mathrm{~ms}$, respectively). There also was a significant target-location main effect, $F(4,84)=3.82, p<.05$, as well as a significant Distracter Presence $\times$ Target Location interaction, $F(4,84)=4.60, p<.01$. That indicated that RTs were longest for Target 1 when there was no distracter present.

Time to peak velocity. There was a significant main effect of target location, $F(4$, $84)=226.61, p<.001$, indicating longer TTPVs for targets located further away ( $M s=193,211,235,246$, and $258 \mathrm{~ms}$ for Targets 1, 2, 3, 4, and 5, respectively). The distracter presence main effect was also significant, $F(1,21)=6.47, p<.05$, indicating longer TTPVs in the presence of a distracter (226 vs. $230 \mathrm{~ms}$, respectively, for trials without and with a distracter; see Figure 2). The Distracter Presence $\times$ Target Location interaction was nonsignificant, $F(4,84)=1.79, p>.1$.

Time after peak velocity. The significant target-location main effect, $F(4,84)=$ $51.93, p<.001$, indicated longer TAPVs for targets located further away $(M \mathrm{~s}=219$, $239,256,276$, and $316 \mathrm{~ms}$ for Targets 1, 2, 3, 4, and 5, respectively). All $F$ values involving distracter presence were nonsignificant (all $p s>.5$ ), indicating that the presence of a distracter did not affect time after peak velocity (see also Figure 2).

Peak velocity. Target location significantly affected the maximum movement velocity attained during the response, $F(4,84)=310.86, p<.001$. Targets located further away were associated with higher PVs $(M \mathrm{~s}=43.8,52.9,60.7,69.2$, and $74.9 \mathrm{~cm} / \mathrm{s}$ for Targets $1,2,3,4$, and 5 , respectively). The distracter-presence main effect was also significant, $F(1,21)=11.46, p<.005$, indicating that the presence of a distracter lowered PV $(M \mathrm{~s}=60.8$ and $59.8 \mathrm{~cm} / \mathrm{s}$, respectively, for trials without and with a distracter).

Percentage error. There was a significant target-location main effect, $F(4,84)=$ $3.83, p<.001$, indicating more errors when responding to Target $4(\mathrm{Ms}=4.2 \%$, $4.0 \%, 4.6 \%, 7.7 \%$, and $6.4 \%$, respectively, for Targets $1,2,3,4$, and 5). All $F$ values regarding distracter presence were nonsignificant (all $p \mathrm{~s}>.6$ ). The overall error rate was $5.4 \%$.

\section{Analysis of Distracter Location}

Reaction time, time after peak velocity, and percentage errors. All $F$ values regarding distracter location were nonsignificant (all $p \mathrm{~s}>.6$ ), indicating that near and far distracters did not differentially interfere with these measures. 
Time to peak velocity. There was a near-significant distracter location main effect, $F(1,21)=3.71, p=.068$. That refers to the tendency for more time to peak velocity interference with near compared with far distracters $(M \mathrm{~s}=5$ and $2 \mathrm{~ms}$ for near and far distracters, respectively).

Peak velocity. Near and far distracters differentially affected the maximum movement velocity attained during the response, $F(1,21)=7.46, p<.05$. That is, whereas near distracters caused a robust decrease in peak velocity, far distracters did not seem to affect peak velocity $(M \mathrm{~s}=-1.7 \mathrm{~cm} / \mathrm{s}$ and $-0.1 \mathrm{~cm} / \mathrm{s}$, respectively).

\section{Discussion}

With the large target-distracter separation, interference occurred only in the time to peak velocity and not in the time after peak velocity. Moreover, there was a tendency for a proximity-to-hand effect in time to peak velocity, with near distracters tending to produce more interference than did far distracters. In addition, near distracters lowered peak velocity, whereas far distracters had no effect on peak velocity, which was also the case in the previous experiment.

The time to peak velocity and peak velocity data are in line with the hypothesis that with large target-distracter separations, interference occurs in the preplanned portion of the response, and the pattern of interference is action centered (Tipper et al., 1992).

The present observation that time to peak velocity and peak velocity (i.e., the preplanned components of the response) showed a proximity-to-hand effect supports the Visuomotor Processing Hypothesis proposed by Meegan and Tipper (1999). That hypothesis suggests that the faster a reaching movement can be made to a location, the more interference a distracter at that particular location will produce. That is because the efficiency of visuomotor processing (i.e., response planning and execution) depends on the location of the stimulus. More specifically, near locations appear to have a visuomotor processing advantage relative to far distracters, which explains the occurrence of a proximity-to-hand effect (Meegan \& Tipper, 1998).

\section{GENERAL DISCUSSION}

In the present study, we investigated distracter interference with both small (5-mm) and large $(20-\mathrm{mm})$ target-distracter separations, and we separated response time into reaction time, time to peak velocity, and time after peak velocity. On the one hand, with the small target-distracter separation in Experiment 1 , we observed distracter effects in the early and later portions of the movement. That is, near distracters decreased peak velocity, whereas far distracters had no significant effect on peak velocity, which suggests an early locus of distracter interference. In addition, distracters prolonged the time after peak velocity, 
indicating a later locus of interference. Moreover, that interference effect was symmetric (i.e., similar for near and far distracters), which suggested the use of an environment-centered frame of reference. On the other hand, with the large target-distracter separation in Experiment 2, distracter interference occurred in the time to peak velocity and, moreover, showed a proximity-to-hand effect. Again, near distracters decreased peak velocity, whereas far distracters did not affect peak velocity. The proximity-to-hand effects in both time to peak velocity and peak velocity suggest the predominance of an action-centered frame of reference in the control of the preplanned portion of the response.

The present results suggested that target-distracter separation was an important determinant of the temporal locus of interference in selective reaching. To substantiate that claim statistically, we performed a between-experiment analysis of variance, by using TTPV and TAPV as dependent variables. In that analysis, distracter presence (without vs. with distracter) was the within-subject variable, and target-distracter separation was the between-subjects variable. For both TTPV and TAPV, the Distracter Presence $\times$ Target-Distracter Separation interaction was significant, $F(1,36)=5.52, p<.05$, and $F(1,36)=4.18, p<.05$, respectively, thereby bolstering the claim that distracter interference was different for the small and large target-distracter separations.

Pratt and Abrams (1994) also partitioned movement time into time to peak velocity and time after peak velocity. In their study, the participants were required to move a handle so that a cursor on a screen moved toward a target. The target was on some occasions accompanied by a distracter (target-distracter separation was 30 $\mathrm{mm})$. The results showed that time after peak velocity was longer for trials with near distracters compared with trials with far distracters (i.e., a proximity-to-hand effect). There was no difference in time to peak velocity as a function of distracter location. Pratt and Abrams' results were not consistent with our findings. That is, whereas Pratt and Abrams found action-centered interference in time after peak velocity, we found action-centered interference in time to peak velocity. The exact cause of that inconsistency remains unclear, but methodological differences may have contributed to it. For example, Pratt and Abrams used an indirect pointing task in which handle rotations below a display were mapped onto cursor movements on the display. Moreover, they did not differentiate between trials with and without discrete movement modifications. That may be an important distinction, as we explain hereinafter.

In Experiment 1, all the stimulus locations were within an array of $7 \mathrm{~cm}$, indicating that the combined target-distracter location did not change much with every possible target-distracter combination. As a consequence, the participants may have adopted a strategy of consistently programming an averaged response that was then corrected online and that resulted in symmetric interference effects. However, in an explicit test of that hypothesis (Keulen et al., 2003), we observed results that were at variance with the hypothesis. That is, we manipulated target-distracter separation within the 7-cm array of stimulus boxes of Experiment 1 . Thus, for both 
the small and the large target-distracter condition the general target-distracter location remained relatively stable. The results showed that interference was environment centered with the small target-distracter separation. However, with the large separation, the distracter interfered in an action-centered manner. Those results rejected the strategy account of the results of Experiment 1.

With both the small (Experiment 1) and the large (Experiment 2) targetdistracter separation, we observed that distracters facilitated the RTs. That is, RTs were shorter in the presence of a distracter compared with when the target was presented alone. However, that facilitatory effect seemed to be larger with the large target-distracter separation than with the small target-distracter separation (i.e., 18 vs. $8 \mathrm{~ms}$, respectively). Indeed, a between-experiment analysis that used RT as a dependent variable, distracter presence (without vs. with distracter) and target location (1, 2, 3, 4, and 5) as independent variables, and target-distracter separation (small vs. large) as a between-subjects variable yielded a significant Target-Distracter Separation $\times$ Distracter Presence interaction, $F(1,36)=5.545$, $p<.05$, which indicated more facilitation with the large target-distracter separation than with the small target-distracter separation. An explanation for the smaller facilitation effect with the small target-distracter separation is provided by the significant Target-Distracter Separation $\times$ Distracter Presence $\times$ Target Location interaction, $F(4,144)=4.067, p<.01$. That interaction indicated that the larger facilitation effect with the large target-distracter separation was most probably owing to the relatively large amount of RT facilitation that occurred when the target was presented at the location closest to the starting position of the hand $(M \mathrm{~s}=$ $40,10,3,18$, and $19 \mathrm{~ms}$, respectively, for Targets $1,2,3,4$, and 5). It is important to note that the $40-\mathrm{ms}$ facilitation effect was the result of a relatively long RT for Target 1 in the no-distracter condition. To test whether that could account for the difference in facilitation between the small and the large target-distracter separation, we performed an additional between-experiments analysis leaving out the trials in which the target was presented at location 1. Now, both the Target-Distracter Separation $\times$ Distracter Presence interaction and the Target-Distracter Separation $\times$ Distracter Presence $\times$ Target Location interaction were nonsignificant (all $p s>$ $.5)$, indicating that the amount of facilitation was similar for the small and the large target-distracter separation $(M \mathrm{~s}=12 \mathrm{vs} .13 \mathrm{~ms}$, respectively). It may have been that in the large target-distracter separation condition, the participant's hand obscured the target location closest to the hand, thus hampering the ability to detect a stimulus that appeared at that location and, as a result, increasing the RT for that location.

There are several accounts of distracter effects on kinematic measures such as movement trajectory and peak velocity. On the one hand, Tresilian (1998) proposed what is referred to as the obstacle account. According to that account, people maintain a minimum distance between their limb segments and nontarget objects within the workspace; consequently, they slow down because a reduced speed helps to ensure that they do not make contact with the obstacle. The obstacle 
account suggests that distracter effects are a result of an avoidance strategy. On the other hand, Tipper and colleagues (Howard \& Tipper, 1997; Tipper, Howard, \& Jackson, 1997) observed that movement trajectories seemed to deviate away from nontarget objects even when they were not direct obstacles. That led Tipper and colleagues to conclude that kinematic distracter effects are the result of an inability to effectively ignore the nontarget. More specifically, one assumes that both the target and nontarget are processed in parallel, and that they evoke competing responses. As a result, a response that contains both target and nontarget components is activated. If that interfering activation is not inhibited, then the trajectory of the moving hand will deviate toward the distracter location. The strength of the interfering activation depends on the location of the nontarget. That is, objects located between the hand and the target produce stronger interfering activation than do nontargets beyond the target. Thus, distracters close to the starting position of the responding hand will be associated with larger deviations toward the distracter location than will be distracters beyond the target, if they are not inhibited. On the one hand, the present results did not support the obstacle account. For one thing, the distracters were not real physical obstacles. Moreover, according to the obstacle avoidance account, participants slow down when approaching the distracter. That would imply that for both the small and the large target-distracter separation, the time spent after peak velocity would be longer with the near distracter compared with the far distracter, and that was clearly not the case. On the other hand, the peak velocity data seemed to support the parallel processing account proposed by Tipper et al. (1997). That is, near distracters lowered peak velocity, whereas far distracters had no significant effect on peak velocity. Thus, it seems that in the case of a near distracter, the response toward the target contained distracter components, because a movement toward the distracter location was associated with a lower peak velocity than was a movement toward the target location. The observation that a far distracter had no significant effect on peak velocity indicated that distracters beyond the target produced less or no interference.

As mentioned heretofore, because the percentage of trials containing a discrete movement modification was relatively small, we excluded those trials from analyses. At this point, we would like to provide some insight into the kinematics of those trials. We calculated mean reaction time, time to peak velocity, peak velocity, and time after peak velocity for trials both with and without discrete movement modifications. ${ }^{2}$ The results showed that trials with and without discrete movement modifications seemed to differ mainly with regard to the magnitude of peak velocity and the duration of the time after peak velocity. As we expected, the time after peak velocity was substantially longer in the presence of movement modifications ( $M \mathrm{~s}=367 \mathrm{~ms}$ and $233 \mathrm{~ms}$, for trials with and without discrete movement modifications, respectively, averaged across Experiments 1 and 2). Furthermore, peak velocity was higher for trials with movement modifications compared with trials without movement modifications $(M \mathrm{~s}=77.1 \mathrm{~cm} / \mathrm{s}$ and $74.3 \mathrm{~cm} / \mathrm{s}$, for 
trials with and without discrete movement modifications, respectively, averaged across Experiments 1 and 2). These findings are consistent with the notion that high-velocity initial impulses, compared with low-velocity impulses, are more likely to require error correction owing to the lack of accuracy (Meyer et al., 1988). Reaction times and time to peak velocity were not substantially different for trials with and without movement modifications ( $M \mathrm{~s}=306 \mathrm{~ms}$ vs. $303 \mathrm{~ms}$ and $212 \mathrm{~ms}$ vs. $210 \mathrm{~ms}$, for reaction times and times to peak velocity, respectively). In sum, the extremely large difference in time after peak velocity between trials with and without discrete movement modifications suggested qualitatively different underlying control mechanisms, and therefore recommends to differentiate between the two types of trials.

In conclusion, the present study provided evidence for the hypothesis that target-distracter separation is an important determinant of the temporal locus of distracter interference in selective reaching. The separation between target and distracter determines which selection problem or problems need to be solved and, in turn, the specific selection problem determines when the problem needs to be solved, and what frame of reference it might benefit from. We have demonstrated that distracters affect the preplanned portion of the response when they interfere with determining the general location of the target. That is because participants need to determine the general location of the target area to bring the hand from the starting point toward the vicinity of the target. But when the distracter interferes with distinguishing the exact location of the target, the online-controlled portion of the response is affected because, for the participant to accurately terminate the movement at the target, he or she must distinguish the exact target location.

\section{NOTES}

1. First, we established the peak velocity. The velocity profile was then traversed backwards in time until the velocity fell below $2 \mathrm{~cm} / \mathrm{s}$. That point was defined as the beginning of the movement. The end of the movement was defined as the point in time following peak velocity at which the absolute velocity of the pen tip fell below $2 \mathrm{~cm} / \mathrm{s}$ for $150 \mathrm{~ms}$. Then, a search was performed from peak velocity to the end of the movement for the possible initiation of a discrete movement modification. That is, a negative to positive zero crossing in the acceleration trace. To qualify as a correction phase, the absolute maximum in the acceleration trace in between the negative to positive zero crossing and the subsequent positive to negative zero crossing in the acceleration trace had to be at least $150 \mathrm{~cm} / \mathrm{s}^{2}$. Furthermore, the duration between the initiation of the movement modification and the end of the movement had to be at least $60 \mathrm{~ms}$, and the distance travelled during that time had to be at least $1 \mathrm{~mm}$. When neither of those criteria was met, a search for the next negative to positive zero crossing in the acceleration trace was performed. That was repeated until a movement modification that met all the aforementioned criteria was met, or until the end of the movement. In those cases in which there was no movement modification, the end of the movement was repositioned at the point after peak velocity at which the absolute velocity fell under $2 \mathrm{~cm} / \mathrm{s}$ for the first time. The movement modifications we identified by using the aforementioned 
criteria included both continuations in the initial movement directions (following a target undershoot) as well as reversal movements (following a target overshoot). That was because the acceleration profile was the first-order derivative of the absolute velocity profile, and the absolute velocity was independent of the direction of the movement. However, because we used absolute velocity, we cannot differentiate between the two types of movement modifications.

2. Because of the large between-subjects variability in the percentage of trials that contained a discrete movement modification, we chose to use the data from those participants who had at least $10 \%$ of trials containing a discrete movement modification. We included 8 out of 16 participants for Experiment 1 and 10 out of 22 for Experiment 2. We calculated the mean RTs, TTPVs, PVs, and TAPVs in the no-distracter and distracter conditions, both for the trials with and without discrete movement modifications. We then averaged across the no-distracter and distracter conditions to arrive at the values reported in this article.

\section{REFERENCES}

Fischer, M. H., \& Adam, J. J. (2001). Distractor effects on pointing: The role of spatial layout. Experimental Brain Research, 136(4), 507-513.

Howard, L. A., \& Tipper, S. P. (1997). Hand deviations away from visual cues: Indirect evidence for inhibition. Experimental Brain Research, 113(1), 144-152.

Jeannerod, M., \& Prablanc, C. (1983). Visual control of reaching movements in man. In J. E. Desmedt (Ed.), Motor control mechanisms in man (pp. 13-29). New York: Raven.

Keulen, R. F., Adam, J. J., Fischer, M. H., Kuipers, H., \& Jolles, J. (2002). Selective reaching: Evidence for multiple frames of reference. Joumal of Experimental Psychology: Human Perception and Performance, 28(3), 515-526.

Keulen, R. F., Adam, J. J., Fischer, M. H., Kuipers, H., \& Jolles, J. (2003). Distractor interference in selective reaching: Dissociating distance and grouping effects. Journal of Motor Behavior, 35(2), 119-126.

Khan, M. A., Franks, I. M., \& Goodman, D. (1998). The effect of practice on the control of rapid aiming movements: Evidence for an interdependency between programming and feedback processing. The Quarterly Journal of Experimental Psychology A, 5l(2), $425-444$.

KIKO Software. (1999). OASIS (Version 8.33) [Computer software]. Nijmegen, The Netherlands: Author.

Kudoh, N., Hattori, M., Numata, N., \& Maruyama, K. (1997). An analysis of spatiotemporal variability during prehension movements: Effects of object size and distance. Experimental Brain Research, 117(3), 457-464.

Meegan, D. V., \& Tipper, S. P. (1998). Reaching into cluttered visual environments: Spatial and temporal influences of distracting objects. The Quarterly Journal of Experimental Psychology, 5I(2), 225-249.

Meegan, D. V., \& Tipper, S. P. (1999). Visual search and target-directed action. Journal of Experimental Psychology: Human Perception and Performance, 25(5), 1347-1361.

Meyer, D. E., Abrams, R. A., Kornblum, S., Wright, C. E., \& Smith, J. E. (1988). Optimality in human motor performance: Ideal control of rapid aimed movements. Psychological Review, 95(3), 340-370.

Nickerson, R. S. (1973). Intersensory facilitation of reaction time: Energy summation or preparation enhancement? Psychological Review, 80(6), 489-509.

Pratt, J., \& Abrams, R. A. (1994). Action-centered inhibition: Effects of distractors on movement planning and execution. Human Movement Science, 13(2), 245-254. 
Tipper, S. P., Howard, L. A., \& Houghton, G. (1998). Action-based mechanisms of attention. Philosophical Transactions of the Royal Society of London, Series B, 353(1373), 1385-1393.

Tipper, S. P., Howard, L. A., \& Jackson, S. R. (1997). Selective reaching to grasp: Evidence for distractor interference effects. Visual Cognition, 4, 1-38.

Tipper, S. P., Lortie, C., \& Baylis, G. C. (1992). Selective reaching: Evidence for actioncentered attention. Journal of Experimental Psychology: Human Perception and Performance, 18(4), 891-905.

Tresilian, J. R. (1998). Attention in action or obstruction of movement? A kinematic analysis of avoidance behavior in prehension. Experimental Brain Research, 120(3), 352-368.

Manuscript submitted September 2003

Revision accepted for publication February 2004 
Copyright of Journal of General Psychology is the property of Heldref Publications and its content may not be copied or emailed to multiple sites or posted to a listserv without the copyright holder's express written permission. However, users may print, download, or email articles for individual use. 